\title{
The Role of Fathers in Child and Family Health
}

\author{
Michael W. Yogman and Amelia M. Eppel
}

\section{Introduction}

The involvement of fathers in their children's health and development has come to the fore of recent research, including several national longitudinal studies on families, such as the Fragile Families and Child Wellbeing Study. Academic studies, policy initiatives and socio-economic forces have documented the variety of ways enhanced involvement of fathers influences the health and development of their children. Twenty-First Century fathers are more involved in caretaking of their children and see parenting as central to their identity (Livingston and Parker 2019). Their involvement right from birth is beneficial to their child in many ways, and preparation during pregnancy increases their involvement (Teitler 2001). Challenges remain, however, especially for the 24 million children who live without a father in their home (Jones and Mosher 2013). However, instead of focusing on fathers as the absent figure in children's lives, policies are beginning to reflect the evidence that fathers have significant family involvement. This can be seen especially in the paid family leave laws created by a number of states (Connecticut, New Jersey, Rhode Island, Massachusetts) which have been implemented to support father-infant attachment (National Conference of State Legislature 2015). In spite of this, concerns about career development still discourage many men from taking advantage of family leave (Halverson 2003; see also later chapters in this volume).

M. W. Yogman $(\bowtie)$

Department of Pediatrics, Harvard Medical School, Boston, MA, USA

e-mail: mwyogman01@gmail.com

A. M. Eppel

Department of Integrated Studies in Education, McGill University, Montreal, QC, Canada e-mail: amelia.eppel@mail.mcgill.ca 
Major socioeconomic and cultural changes have led to more fathers having the opportunity to contribute at home, or to become stay-at-home dads in families where the mother sustains the family's income. These cultural changes include (1) the growth in women's educational achievement and economic power and (2) the great recession of 2008 with its severe impact on paternal employment (Yogman et al. 2016). Fathers are increasingly attendant at their children's births, more involved in their children's education and health care, experience similar work-family conflicts to mothers, and have unique relationships with their children (Yogman et al. 2016). Fathers have a consequential impact on their children's nutrition, exercise, play, and, eventually, their own parenting behavior. In this chapter, particular emphasis will be placed on father involvement across the stages of childhood, and the influence of fathers' physical and mental health on their children and wider family dynamic. The implications of father involvement for child health, and considerations for future research and policy areas will also be discussed.

\subsection{Who Is a Father?}

Before considering these trends and their implications, we must re-examine the role of "father" as a diverse category that challenges outdated notions of the heterosexual nuclear family. The working definition used in this review is that of male-identified adults who are most involved in the caregiving of a child, regardless of living situation, marital status or biological relation (Yogman et al. 2016). The role of father may be manifest in a multitude of ways: as the primary parent, as one of two primary parents, or as a secondary parent. They may be a biological, foster, or adoptive father, a stepfather, or a grandfather (Gogineni and Fallon 2013). Some children have a single father or two parents who are both fathers. Children may also have both a biological, non-resident father and a stepfather. In some families, children have three or four adults in a parenting role, with one or two of them being fathers. Some children do not have a male-identified figure involved in raising them. Within these configurations, fathers may be legal custodians of the child or not, resident or non-resident. In this chapter, fatherhood will be considered from these many perspectives, while maintaining a focus on fathers as part of the heterosexual couple, as the bulk of research lies within this framework.

\section{Changing Trends in Parenting}

The number of fathers in the United States is estimated at about 72 million at the last census survey, conducted in 2014 (US Census Bureau 2020), increasing from 60.1 million in the year 2000 (US Census Bureau 2013). The number of single fathers raising children in 2019 was two million-a significant increase from that figure in 2000 (Yogman et al. 2016). Single fathers now make up $18 \%$ of the single parent 
population. Although 1 in 6 fathers do not reside in the same home as their children, only $1-2 \%$ of them have no contact or participation in their children's lives (Jones and Mosher 2013). Most often this is because they meet a new partner and father a new infant.

Estimated at a total of 98,000 in 2003 (Yogman et al. 2016), there are now around 191,000 fathers who stay home to care for their children (US Census Bureau 2020). Significantly, this increase happened predominantly in the years 2003-2007, during which stay-at-home fathers increased by $60 \%$ to 159,000 (US Census Bureau 2013). According to a recent Pew Research Center report, this census data is in fact a gross underestimate; in 2012 there were 2.2 million stay-at-home fathers (Livingston 2014). Eight percent of these men were home because they were unable to find work, another $8 \%$ were in school and $11 \%$ were retired, while $24 \%$ chose to stay home to care for their home or family (an increase from $4 \%$ in 1989). A significant $40 \%$ were home because of illness or disability (Livingston 2014). Although most stay-at-home parents are mothers, fathers' share of stay-at-home parenting increased from $10 \%$ in 1989 to $16 \%$ in 2012 , caring more than 200,000 children full-time and almost two million preschoolers part-time (Livingston 2013, 2014).

Demographic research from 2016 has shown that parenting is as central to the identities of this generation's fathers as it is to its mothers: $57 \%$ of fathers in a 2015 survey reported that parenting was extremely important to their identity, compared with 58\% of mothers (Livingston and Parker 2019). Fifty-four percent of fathers also reported that parenting was rewarding all of the time, as did $52 \%$ of mothers. This data shows the centrality with which adults identifying as both mothers and fathers value their role as parents. Fathers in 2016 also reported taking care of their children on average $8 \mathrm{~h} /$ week, three times as much as fathers reported in 1965. Comparatively, mothers still spend more time taking care of their children: on average $14 \mathrm{~h} /$ week in 2016. Sixty-three percent of fathers report not feeling as though they spend enough time with their children, compared with only $35 \%$ of mothers. Additionally, only $39 \%$ of fathers in 2015 felt that they were doing a "very good job" raising their children, compared with $51 \%$ of mothers. This shows a discrepancy in the sense of competence that mothers and fathers on average feel as parents, which also aligns with the amount of time spent caring for their children.

In the Pew study both mothers and fathers cited work obligations as the main reason for spending less time with their children than they would like (Livingston and Parker 2019). Only $27 \%$ of heterosexual two-parent families with children under 18 are supported solely by a father's income: $20 \%$ less than in 1970 . While only $2 \%$ of families were solely supported by a mother's income in 1970, this hasn't significantly increased over the past 50 years, rising only to 5\% in 2016 (Livingston and Parker 2019). Clearly, this data reflects only one part of the father population, yet it reveals a clear trend toward a more equal share of income and working patterns in heterosexual two-parent families. Despite this, $76 \%$ of Americans surveyed in a 2017 study felt that fathers faced "a lot of pressure" to support their family financially (Parker et al. 2017b). Only 40\% said the same of mothers, reflecting the data which shows only a limited increase since 1970 (from $2 \%$ to 5\%) in families supported solely by a mother's income (Livingston and Parker 2019). 
Along the same lines, 53\% of Americans surveyed in 2017 still buy into the gender stereotype that, breast-feeding aside, mothers are better at caring for infants (Livingston and Parker 2019). Only 1\% felt that fathers do a better job, while $45 \%$ felt mothers and fathers are equally able to care for children. At the same time, $64 \%$ felt that mothers and fathers have different approaches to parenting. Two thirds of fathers felt this had a biological basis, while, conversely, two thirds of mothers felt this was due to socialized gender roles and expectations. $56 \%$ of those reporting gender differences in parenting said that these differences were a good thing. Based on this data, it seems that gender stereotyping is more significantly practiced and believed in by fathers, which equally impacts on their parenting. Only $53 \%$ of fathers felt it was a good thing to encourage their sons to participate in activities typically associated with girls, compared with $72 \%$ of mothers. Interestingly, the data shows that parents saw their daughters participating in typically "boy" activities more positively: $69 \%$ of fathers, and $83 \%$ of mothers. These data points raise important questions about masculinity and its role in creating and perpetuating stereotyped views of gender. This has clear implications for professionals supporting fathers in their parenting.

\section{Father Involvement Across Childhood}

Research has found that father involvement in a child's life right from birth is beneficial to children in a myriad of ways but needs to be conceptualized as part of a supportive family system (Cabrera et al. 2017; Pruitt et al. 2017). The Pew Research Center trends reflect an increased engagement in parenting by fathers over the past few decades. As a result, fathers have more involvement in their children's lives than ever before. This involvement, however, looks different than it has in the past. One in six fathers do not live with their children, however only 1-2\% of these are not involved with their children to any degree (Jones and Mosher 2013). There is thus a clear need to consider fatherhood from perspectives that value involvement in all its forms. Paternal involvement in a child's life has been linked to positive child outcomes, including reduced obesity and asthma, and improved mental health and cognition (Allport et al. 2018). The nature of these benefits are complex and deserve careful attention in order to ascertain what makes father involvement unique as well as how it can be nurtured. It is important that this be considered without excluding the interplay of other salient factors, such as the overall quality of family relationships and socioeconomic status. In order to reflect on the ways in which fathers play a unique role in their children's lives research findings on father involvement at the prenatal, infant, childhood, and adolescent stages will be summarized. 


\subsection{Prenatal}

Paternal involvement begins prenatally. This is exhibited in practical terms by attendance at health care visits and at the child's birth (Teitler 2001). Father involvement in the prenatal period can also be seen in men's biological responses to a partner's pregnancy, such as in the presentation of Couvade syndrome (or 'sympathetic pregnancy'), where a father may experience insomnia, restlessness, and excess weight gain during their partner's pregnancy (Conner and Denson 1990). The impacts of father involvement during pregnancy are profound: one study found that it correlated with mothers being 1.5 times more likely to receive first-trimester prenatal care (Teitler 2001). Father involvement during pregnancy has also been associated with a $36 \%$ reduction in smoking, compared with mothers whose partners were not involved (Martin et al. 2007). In two studies a correlation was also found between a lack of paternal involvement and adverse birth outcomes in certain racial and ethnic populations (Alio et al. 2011a, b). These findings suggest that increased paternal involvement can have a positive impact on birth outcomes, which may be important for decreasing the racial and socioeconomic disparities in infant morbidities. Overall, prenatal paternal involvement in heterosexual couples (as well as residence at birth) was the strongest predictor of continued paternal involvement by the time a child reached 5 years old (Shannon et al. 2009).

\subsection{Infancy}

Most fathers are now present at the birth of their children, although the median amount of time new fathers take off from work is still much lower at only 1 week, compared with mothers' 11 weeks (Livingston and Parker 2019). Parental leave issues aside, there are numerous benefits to fathers' involvement with their newborn children evidenced by medical, developmental, and sociological research. One such study compared father skin-to-skin care with conventional cot care during the first $2 \mathrm{~h}$ after birth (Erlandsson et al. 2007). Newborn infants who were given skin-to-skin care by their father became drowsy more quickly, cried less and exhibited fewer rooting and sucking behaviors than those in cot care These findings imply that fathers can play an important role in this crucial stage after birth, a time where mothers' care is usually prioritized. To enhance paternal involvement at this stage, research has shown that simple interventions such as bathing and changing demonstrations and father support groups increase sustained father-infant connection (Yogman 1982).

During infancy, fathers have been found to have similar psychological experiences as mothers and have equally positive interactions with their infants (Yogman 1982). Interestingly, in one prospective study, children with fathers who were more involved with them in infancy displayed a lower level of mental health symptoms at age 9 than those with minimal paternal input in infancy (Boyce et al. 2006). Of 
significant import was the finding that this kind of involvement could serve to mediate detrimental effects from maternal depression.

Studies show that fathers are more likely to play with their infants than mothers, and that the play between father and infant tends to be of a higher intensity (Yogman 1982; Yogman et al. 1983). Taking cues from their infant, the fathers studied were able to support and help regulate their child's positive emotional state during social interactions by synchronizing arousal rhythms with their infants just as successfully as mothers (Yogman et al. 1983; Feldman 2003). This research also found that the quality of interactions (especially in play) was different between male-identified parents and their children than female-identified parents and their children. The interactions between fathers and their infants tended toward more intense peaks of positive emotion than with mothers. These high intensity interactions with fathers may encourage children's exploration and independence, while the less intense interactions with mothers may provide safety and balance (Raeburn 2014; Yogman 1982). A particularly notable finding was that same-sex parent-infant pairs were more responsive to each other's affective states, making co-regulation of emotions through social interaction with the father most important for their biologically male children (Feldman 2003). Whether this is based on socialized expectations of similarity with one's own sex, or on actual biological similarities is unclear.

Despite these findings, which reveal the important role a father can play in a newborn child's life, paternity leave legislation allows for a significantly lesser degree of involvement. In the U.S., the Family and Medical Leave Act (FMLA) is the only federal legislation that allows parents to take leave after the birth or adoption of a child, and to care for a sick family member. The FMLA grants 12 weeks of unpaid leave, and only $59.4 \%$ of the workforce are actually covered by it, according to 2014 data (Kleeman et al. 2014). Additionally, $46 \%$ of people who do have access to FMLA do not take it as they are unable to financially afford to. Some states have begun to address this issue by instituting paid family leave policies. In one 2011 study, $85 \%$ of fathers working for Fortune 500 companies took some time off after the birth of a child, but this was predominantly only 1-2 weeks and unpaid (Harrington et al. 2013). Ninety percent of working fathers in this research reported feeling as though their supervisor expected no change to occur in their working patterns as a result of becoming a father. With these expectations being commonplace, the involvement of fathers in their newborn child's life is minimized, a factor which must be taken into serious consideration by policymakers seeking to positively impact families through greater father involvement.

\subsection{Childhood}

The benefits of paternal involvement persist through childhood, although most studies do not assert a greater benefit to having a male-identified parent than of having two parents, regardless of their gender (Yogman et al. 2016). However, examples abound in which the presence of a father has positive impacts on children's 
lives. In studies of chronic childhood disease, children from father-absent families had poorer adherence to treatment, psychological adjustment, and health status than those with fathers present (Wysocki and Gavin 2006). While the reasons for this are complex, the data shows that father involvement in the healthcare setting has a positive impact, which must be considered by professionals seeking to support families of children with chronic illnesses.

Father involvement with their children through play has been the focus of most studies of father-child interaction in early and middle childhood. In one study, when fathers were more involved in infancy, children had lower mental health symptoms at age 9 than those whose parents did not play, communicate and care for them in infancy (Boyce et al. 2006). Father-child play in the preschool years has been found to decrease externalizing and internalizing behavior problems, despite, or perhaps because of the tendency of fathers to encourage more "roughhouse" play with their children (Jia et al. 2012). A positive correlation between father involvement and their children's social competencies and pro-social behaviour has also been found (Chang et al. 2007). Furthermore, the influence of maternal depressive symptoms on child problem behaviors varied by the level of the father's positive involvement. This information suggests that the influence of involved fathers may compensate for the negative influence of maternal depression (e.g., reduced responsiveness to a child's socioemotional needs), thereby reducing the risk of problem behaviors in children of families experiencing maternal depression.

Another significant contribution that fathers can make to their child's development is in the realm of language. One study linked fathers' language input to children's early language development, finding that fathers' language input to their children at 2 years old made a unique contribution to children's later expressive language skills at 3 years old, after parent education and quality of childcare was considered (Pancsofar and Vernon-Feagans 2006). Despite this finding, mothers during the first 6 months with their infants used significantly more expressive language with their children than fathers did, yet it was the father's language contributions which correlated with most impactful language development. One suggested explanation is the possibility that fathers are more likely to introduce new words, while mothers may tailor word choice to the child's known vocabulary (Raeburn 2014). The influence of father involvement on children's language development certainly merits further study based on these results.

\subsection{Adolescence}

Father involvement during their children's adolescence can be significant and formative. Several large-scale studies have shown that father involvement is associated with a decrease in the likelihood of risk behaviors in adolescence, if the quality of the parent-child relationship is strong. In one such study, a positive father-child relationship was shown to predict a reduced engagement in risky behaviors by adolescents (Bronte-Tinkew et al. 2006). This proved to be more significant for 
male adolescents, suggesting that positive father-son relationships are important for mitigating risk behavior in adolescence. Studies also showed that adolescents whose nonresident fathers were involved in their lives have been shown to be less likely to begin smoking regularly (Menning 2006). These findings suggest that strong fatherchild relationships can have a significant positive influence on adolescents.

Father engagement has also been correlated with improved cognitive development, a meta-analysis of studies has shown (Sarkadi et al. 2008). In addition, positive relationships with their father was found to be a predictor of lower rates of behavioral problems in adolescent boys, and fewer psychological problems in adolescent girls. As a result, it also predicted a decreased rate of delinquency in children of families with low socioeconomic status (Sarkadi et al. 2008). Involvement of fathers with their daughters has also been associated with a later onset of puberty, fewer early sexual experiences, and a lower risk of teen pregnancy (Ellis et al. 2012). It is speculated that this may be as a result of exposure to fathers' pheromones, which have the potential to slow female pubertal development (Raeburn 2014). Father involvement in early childhood, in the context of other highquality family relationships, had the greatest impact on pubertal timing in girls (Ellis et al. 1999). Having an involved father has been associated with greater age-appropriate independence, cognitive development and social skills (Yogman 1982).

While father involvement is clearly important across the span of childhood for the reasons cited above, it is important to note that relationships with two parents regardless of their sex or gender identity is the most significant factor in supporting children's healthy development. Studies have in fact found that same-sex parenting gives no disadvantage: adolescents' psychosocial adjustment, school outcomes, and romantic relationships were stable across family type, with the most well-adjusted children reporting closer relationships with parents (Wainright et al. 2004). In essence, father involvement must be considered crucial both for the unique contribution male-identified parents can make, as well as the part a father plays purely as a parent, regardless of sex or gender identity.

\section{Father Health and Its Impact on Children}

The mental and physical health of fathers has been found to have major impact on the health and development of their children, most saliently in terms of paternal postpartum depression (PPPD). Research on depression in the postpartum period has shown that up to $25 \%$ of fathers experience depression in this time; this increases to 50\% when mothers are also experiencing postpartum depression (Davis et al. 2011; Goodman 2004; Edmondson et al. 2010; Ramchandani et al. 2011; Paulson and Bazemore 2010; Gawlik et al. 2014). New fatherhood increases the likeliness of depression in men: fathers were 1.38 times more likely to be depressed than same aged men who were not fathers (Giallo et al. 2012). One study found that fathers who do not live with their child reported higher depression symptoms during the 
transition to fatherhood, while those who do live with their children had a $68 \%$ increase in depressive symptoms in the child's first 5 years (Garfield et al. 2014). Because of higher rates of several stressors (e.g., racism, unemployment, poverty, incarceration, and homelessness) which disproportionately affect Black fathers, this population is at a higher risk for depression and other mental health conditions (Anderson et al. 2005; Reinherz et al. 1999; Davis et al. 2009). A prior history of depression, sleep deprivation, or having a sick or premature child are additional risk factors for PPPD.

Paternal postpartum depression is frequently under-identified as it is not often screened for, despite the fact that the Edinburgh Postnatal Depression Scale has been validated for use with fathers as well as mothers (Matthey et al. 2001). When PPPD is identified, treatment is often inadequate, as specific resources targeting fathers rather than mothers are currently scarce. Paternal postpartum depression has a different presentation and symptomatology to maternal postpartum depression, therefore treatment needs also to be different (Yogman et al. 2016). Men are more likely to avoid expressing vulnerability, and seek help for mental health issues at lower rates (Mansfield et al. 2003; Rochlen 2005). Men often experience depression in uncharacteristic ways, psychology research shows. It may show up instead as substance misuse, anger and/or violence, interpersonal issues and compulsive behaviors (Cochran 2001). These types of presentations more often lead to relationship stress and domestic violence and can undermine positive attachment behaviors between mother and child, such as breastfeeding (Yogman et al. 2016). It can also explain the discrepancy in the prevalence of postpartum depression between men and women, as PPD may not be the most obvious diagnosis based on typical presentation in men.

Onset of depression in the postpartum period can also occur later for fathers (i.e., up to a year postpartum) than mothers, who usually experience it in the first 3 months postpartum (Goodman 2004). Screening for PPPD should thus be prioritized by healthcare providers throughout the child's first year of life. Research shows that depressed fathers are four times more likely to physically punish their infants and less likely to engage positively with their infants by reading to them (Fletcher et al. 2011; Davis et al. 2011). One study, which asked fathers to rank different aspects of their lives, found that the emotional experience of parenting along with work-life conflict, were the most negative and tiring activities in their life (Kahneman et al. 2004). Significantly, nearly a quarter of fathers have experienced depression by the time their child is 12 years old (Davé et al. 2010).

Recent research shows that paternal depression has negative effects on child behavior, mood, and development in similar ways to the impact caused by maternal PPD (Yogman et al. 2016). The Avon Longitudinal Study of Parents and Children found correlative evidence that paternal depression in the postpartum period increased the likelihood of child behavioral problems in the preschool years, even when maternal depression and other sociodemographic correlates were controlled (Ramchandani et al. 2005). Furthermore, new findings from this study have revealed that daughters of men who had PPPD when they were infants were at a significantly greater risk of experiencing depression at the age of 18 (Gutierrez-Galve et al. 2018). 
Parents' mental health problems have negative impact on their childcare habits, their involvement, and their parenting styles (Yogman et al. 2016). Parents who are depressed are less likely to spend quality time with their young children, provide less nurturing physical contact, and are more likely to express frustration at their children (Davis et al. 2011; Lyons-Ruth et al. 2002). In a study of families enrolled in Head Start programs (a nationwide early childhood education program in the U.S.), depressed fathers were found to be less involved with their infants than fathers who did not report depressive symptoms (Roggman et al. 2002). A reduction in father-child engagement and play, poorer relationships with their partner, and less effective co-parenting, were also associated with depression in fathers who took part in the Fragile Families and Child Wellbeing study (Bronte-Tinkew et al. 2007). It is possible that parental conflict increases the risk of depression in fathers; further research is required to ascertain the most significant influences on paternal mental health and their role in family health and wellbeing (Yogman et al. 2016).

Fathers' physical health also plays a role in their children's health. One example of how a father's physical well-being may affect a child's well-being is in the case of obesity. Current research suggests that when only one member of the parenting couple is in a higher weight status category, it is the father's and not the mother's weight status that is a significant predictor of later child obesity (Brophy et al. 2012; Freeman et al. 2012). This suggests that fathers play an important role in how childhood obesity develops in the family environment.

\section{Diversity of Fathers}

The roles, social expectations, and support needs of fathers are varied. Military families are one example. Among the 200,000 American military personnel currently serving overseas (Bialik 2017), many are fathers and continuity of their relationships with their children during prolonged absences is an ongoing challenge. Around 15\% of military personnel are women (Parker et al. 2017a), meaning that many more mothers serving in the U.S. armed forces are also being deployed, leaving fathers to be single parents, a situation which little support is offered for. Similarly, incarcerated and formerly incarcerated fathers who wish to remain connected to their children are especially important to support, as more than 750,000 U.S. fathers are serving time in prison (Geller et al. 2012). Children growing up without a father face greater risks of homelessness, truancy, school drop-out, and suicide (American Institutes for Research 2013).

According to 2018 census data, there are 485,065 gay male couple households in the U.S., with $9 \%$ of these raising children (US Census Bureau 2018). This data does not include gay fathers who share custody after a divorce, or single gay fathers. By comparison, of the 510,355 gay female couple households in the U.S., 23\% are raising children. Children with gay parents have been found to be comparable to children with heterosexual parents on key psychosocial and developmental outcomes (American Academy of Pediatrics - COPACFH 2013). There is as yet no 
conclusive research on the benefits of having two mothers over two fathers, or vice versa, although the evidence currently points to the fact that having two loving parents regardless of sex or gender identity is key in raising healthy successful children. Adequately supporting fathers to play a central parenting role regardless of their partnership status or sexual orientation remains the most important factor to consider.

Significantly, ethnic and racial differences in fathering have also not been well studied. While definitions of masculinity are beginning to transition from an emphasis on toughness to an emphasis on tenderness, racial differences persist in this domain. In one study, white fathers were more demonstrative with children under age 13 than Black fathers: hugging their children more and telling them they loved them (Child Trends Data Bank 2002). This is, however, an understudied area, and there is no adequate research that has been conducted more recently than the one cited above to compare it to. The important role of fathers in the Black community are nonetheless evident; an intervention program with 8- to 12-year-old Black boys that focused on the parenting skills of nonresident fathers was associated with reduced aggressive behavior in the boys (Caldwell et al. 2014). Parenting by Hispanic fathers, who make up a significant portion of the U.S. father population, is currently under-researched, and undocumented immigrant fathers have not yet been studied at all.

Nonresident fathers are a particularly important group of men to support with ongoing engagement with their children. Forty percent of births are to unmarried women (Parker et al. 2015). However, for the remaining 60\% of children born within a marriage, one in five children will see the breakup of that marriage by the age of 9. Nonresident father relationships are thus exceptionally common. While the adult couple bond may be fractured, these fathers may continue their involvement with their children if adequately supported. Additionally, racial diversity in nonresident fathering must be considered. Black fathers, while more likely to be nonresident than white fathers (24\% versus $8 \%$ ), are found to be more engaged than white nonresident fathers, giving support with dressing, bathing, and reading to their children in the early months (Jones and Mosher 2013; Edin and Nelson 2013). It has been suggested that, while eager to learn about child rearing, many nonresident fathers prefer information from their community and peers than from professionals (Smith et al. 2015).

Another trend in fatherhood that has increased over the past 20 years is men bearing children with multiple partners. Around $17 \%$ of all fathers aged $40-44$ have children with 2 or more partners, and more than $22 \%$ of fathers with 2 or more children have had them with 2 or more partners (Guzzo 2014). These men are typically more engaged with the children of their most recent partner and often provide diminished resources for each child they have (Cancian et al. 2011; Manning and Smock 2000). The diversity of father's roles and social relationships add a level of complexity to understanding the effect fathers have on family health. 


\section{Implications for Future Research and Policy}

Current research suggests that fathers are more involved in parenting than ever before and see that role as central to their identity. Father involvement from birth is beneficial to children in myriad ways. Preparation increases father involvement, especially engagement during pregnancy. Fathers can play a unique role with infants and children as play partners, a role distinct from that of mothers. Although fathers may not initially feel comfortable parenting young infants, simple interventions that normalize apprehension, provide specific advice and have targeted outreach, can produce long lasting effects. Challenges remain with the increase in nonresident fathers, which effects 24 million children, and for which there are limited effective engagement strategies.

There is also a need for research that considers the diversity of fatherhood from perspectives that look beyond the norms of heterosexual two-parent families. While there is some research on parenting in same-sex families, there is scope for development of research into how family structures differ and align across sex and gender roles. Many of the research conclusions cited co-parenting relationships and the family environment as significant context for many of the outcomes and implications. Further exploration of the contextual elements that shape how father involvement and father health impacts children would also help build a more nuanced picture of how these elements function. Much of the existing research suggests that the most important role a father plays to a child is as one of two parents, yet there are many unique ways in which fathers also contribute. Further research in these areas would perhaps help resolve the contention of these seemingly opposing views.

Finally, the two most significant implications for policy are, identifying and treating PPPD—which is both dangerous and underdiagnosed-and supporting paternity leave. Many of the findings stress the importance of the father-child relationship in infancy, but changes in workplace policies, community services and legislation regarding parental leave are essential to produce sustained improvements that will support both mothers and fathers to successfully raise children.

\section{References}

Alio AP, Mbah AK, Kornosky JL, Wathington D, Marty PJ, Salihu HM (2011a) Assessing the impact of paternal involvement on racial/ethnic disparities in infant mortality rates. J Community Health 36(1):63-68

Alio AP, Mbah AK, Grunsten RA, Salihu HM (2011b) Teenage pregnancy and the influence of paternal involvement on fetal outcomes. J Pediatr Adolesc Gynecol 24(6):404-409

Allport BS, Johnson S, Agil A, Labrique AB, Nelson T, Kc A, Carabas Y, Marcell AV (2018) Promoting father involvement for child and family health. Acad Pediatric Assoc 18(7):746-753. https://doi.org/10.1016/j.acap.2018.03.011

American Academy of Pediatrics, Committee on Psychosocial Aspects of Child and Family Health (COPACFH) (2013) Promoting the wellbeing of children whose parents are gay or lesbian. Pediatrics 131(4):827-830 
American Institutes for Research (2013) Guide for father involvement in systems of care. https:// www.air.org/resource/guide-father-involvement-systems-care. Accessed 14 Jun 2013

Anderson EA, Kohler JK, Letiecq BL (2005) Predictors of depression among low-income, nonresidential fathers. J Fam Issues 26(5):547-567

Bialik K (2017) US active-duty military presence overseas is at its smallest in decades. Pew Research Center Fact Tank, Washington, DC. https://wwwpewresearchorg/fact-tank/2017/08/ 22/u-s-active-duty-military-presence-overseas-is-at-its-smallest-in-decades/. Accessed $21 \mathrm{Nov}$ 2020

Boyce WT, Essex MJ, Alkon A, Goldsmith HH, Kraemer HC, Kupfer DJ (2006) Early father involvement moderates biobehavioral susceptibility to mental health problems in middle childhood. J Am Acad Child Adolesc Psychiatry 45(12):1510-1520

Bronte-Tinkew J, Moore KA, Carrano J (2006) The father-child relationship, parenting styles, and adolescent risk behaviors in intact families. J Fam Issues 27(6):850-881

Bronte-Tinkew J, Ryan S, Carrano J, Moore KA (2007) Resident fathers' pregnancy intentions, prenatal behaviors, and links to involvement with infants. J Marriage Fam 69(4):977-990

Brophy S, Rees A, Knox G, Baker J, Thomas NE (2012) Child fitness and father's BMI are important factors in childhood obesity: a school based cross-sectional study. PLoS One 8(5): e36597

Cabrera N, Volling BL, Barr R (2017) Fathers are parents, too! Child Dev Perspect 12(3):152-157

Caldwell HC, Antonakos CL, Assari S, Kruger D, De Loney EH, Njai R (2014) Pathways to prevention: improving non-resident African American fathers' parenting skills and behaviors to reduce sons' aggression. J Child Dev 85(1):308-325

Cancian M, Meyer DR, Cook ST (2011) The evolution of family complexity from the perspective of nonmarital children. Demography 48(3):957-982

Chang JJ, Halpern CT, Kaufman JS (2007) Maternal depressive symptoms, father's involvement, and the trajectories of child problem behaviors in a US National Sample. Arch Pediatr Adolesc Med 161(7):697-703

Child Trends Data Bank (2002) Parental warmth and affection. wwwchildtrendsorg/? indicators $=$ parental-warmth-and-affection. Accessed 24 Mar 2015

Cochran SV (2001) Assessing and treating depression in men. In: Brooks GR, Good GE (eds) The new handbook of psychotherapy and counseling with men, vol 1. Jossey-Bass, San Francisco, pp 3-21

Conner GK, Denson V (1990) Expectant fathers' response to pregnancy: review of literature and implications for research in high-risk pregnancy. J Perinatal Neonatal Nurs 4(2):33-42. https:// doi.org/10.1097/00005237-199009000-00006

Davé S, Petersen I, Sherr L, Nazareth I (2010) Incidence of maternal and paternal depression in primary care: a cohort study using a primary care database. Arch Pediatr Adolesc Med 164 (11):1038-1044

Davis RN, Caldwell CH, Clark SJ, Davis MM (2009) Depressive symptoms in nonresident African American fathers and involvement with their sons. Pediatrics 124(6):1611-1618

Davis RN, Davis MM, Freed GL, Clark SJ (2011) Fathers' depression related to positive and negative parenting behaviors with 1-year-old children. Pediatrics 127(4):612-618

Edin K, Nelson TJ (2013) Doing the best I can. University of California Press, Berkeley

Edmondson OJ, Psychogiou L, Vlachos H, Netsi E, Ramchandani PG (2010) Depression in fathers in the postnatal period: assessment of the Edinburgh postnatal depression scale as a screening measure. J Aff Disord 125(1-3):365-368

Ellis BJ, McFadyen-Ketchum S, Dodge KA, Pettit GS, Bates JE (1999) Quality of early family relationships and individual differences in the timing of pubertal maturation in girls: a longitudinal test of an evolutionary model. J Pers Soc Psychol 77(2):387-401

Ellis BJ, Schlomer GL, Tilley EH, Butler EA (2012) Impact of fathers on risky sexual behavior in daughters: a genetically and environmentally controlled sibling study. Dev Psychopathol 24 (1):317-332 
Erlandsson K, Dslina A, Fagerberg I, Christensson K (2007) Skin-to-skin care with the father after cesarean birth and its effect on newborn crying and prefeeding behavior. Birth 34(2):105-114

Feldman R (2003) Infant-mother and infant-father synchrony: the coregulation of positive arousal. Infant Ment Health J 24(1):1-23. https://doi.org/10.1002/imhj.10041

Fletcher RJ, Feeman E, Garfield C, Vimpani G (2011) The effects of early paternal depression on children's development. Med J Austr 195(11-12):685-689

Freeman E, Fletcher R, Collins C, Morgan PJ, Burrows T, Callister R (2012) Preventing and treating childhood obesity: time to target fathers. Int J Obes 36(1):12-15

Garfield CF, Duncan G, Rutsohn J, McDade TW, Adam EK, Coley RL, Chase-Lansdale L (2014) A longitudinal study of paternal mental health during transition to fatherhood as young adults. Pediatrics 133(5):836-843

Gawlik S, Muller M, Hoffmann L et al (2014) Prevalence of paternal perinatal depressiveness and its link to partnership satisfaction and birth concerns. Arch Womens Ment Health 17(1):49-56

Geller A, Cooper CE, Garfinkel I, Schwartz-Soicher O, Mincy RB (2012) Beyond absenteeism: father incarceration and child development. Demography 49(1):49-76

Giallo R, D'Esposito F, Christensen D, Mensah F, Cooklin A, Wade C, Lucas N, Canterford L, Nicholson JM (2012) Father mental health during the early parenting period: results of an Australian population based longitudinal study. Soc Psychiatry Psychiatr Epidemiol 47 (12):1907-1966

Gogineni R, Fallon AE (2013) The adoptive father. In: Brabender VM, Fallon AE (eds) Working with adoptive parents. Wiley, Hoboken, pp 89-104

Goodman JH (2004) Paternal postpartum depression, its relationship to maternal postpartum depression, and implications for family health. J Adv Nurs 45(1):26-35

Gutierrez-Galve L, Stein A, Hanington L, Heron J, Lewis G, O'Farrelly C, Ramchandani PG (2018) Association of maternal and paternal depression in the postnatal period with offspring depression at age 18 years. JAMA Psychiat 76(3):290-296. https://doi.org/10.1001/jamapsychiatry. 2018.3667

Guzzo KB (2014) New partners, more kids: multiple-partner fertility in the United States. Ann Am Acad Pol Soc Sci 654(1):66-86. https://doi.org/10.1177/0002716214525571

Halverson C (2003) From here to paternity: why men are not taking paternity leave under the family medical leave act. Wisconsin Womens Law J 18(2):257-259

Harrington B, Van Deusen F, Fraone JS (2013) The new dad: a work (and life) in progress. Boston College Center for Work and Family, Boston

Jia R, Kotila L, Schoppe-Sullivan S (2012) Transactional relations between father involvement and preschoolers' socioemotional adjustment. J Fam Psychol 26(6):848-857

Jones J, Mosher WD (2013) Fathers' involvement with their children: United States, 2006-2010. Natl Health Stat Rep 71:1-21

Kahneman D, Krueger AB, Schkade DA, Schwarz N, Stone AA (2004) A survey method for characterizing daily life experience: the day reconstruction method. Science 306 (5702):1776-1780

Kleeman JA, Daley K, Pozniak A (2014) Family and medical leave in 2012: technical report. Abt Associates, Cambridge

Livingston G (2013) Why are dads staying home? Analysis of march current population surveys integrated public use micro data series (IPUMS-CPS). Pew Research Center, Washington, DC. https://www.pewsocialtrends.org/2014/06/05/chapter-2-why-are-dads-staying-home/

Livingston G (2014) Growing number of dads home with the kids. Pew Research Center Social and Demographic Trends Project Blog, Washington, DC. wwwpewsocialtrendsorg/2014/06/05 Accessed 24 Mar 2015

Livingston G, Parker K (2019) 8 facts about American dads. Pew Research Center, Washington, DC. https://www.pewresearch.org/fact-tank/2019/06/12/fathers-day-facts/

Lyons-Ruth K, Wolfe R, Lyubchik A, Steingard R (2002) Depressive symptoms in parents of children under age 3: sociodemographic predictors, current correlates, and associated parenting 
behaviors. In: Halfon N, McLearn KT (eds) Child rearing in America: challenges facing parents with young children. Cambridge University Press, New York, pp 217-259

Manning WD, Smock PJ (2000) "Swapping" families: serial parenting and economic support for children. J Marriage Fam 62(1):111-122

Mansfield AK, Addis ME, Mahalik JR (2003) 'Why won't he go to the doctor?': the psychology of men's help seeking. Int J Mens Health 2(2):93-109

Martin LT, McNamara MJ, Milot AS, Halle T, Hair EC (2007) The effects of father involvement during pregnancy on receipt of prenatal care and maternal smoking. Matern Child Health J 11 (6):595-602. https://doi.org/10.1007/s10995-007-0209-0

Matthey S, Barnett B, Kavanagh DJ, Howie P (2001) Validation of the Edinburgh postnatal depression scale for men, and comparison of item endorsement with their partners. J Aff Disord 64(2-3):175-184

Menning CL (2006) Nonresident fathers' involvement and adolescents' smoking. J Health Soc Behav 47(1):32-46

National Conference of State Legislatures (2015) Labor and employment. www.ncsl.org/research/ labor-and-employment/state-family-and-medical-leave-laws.aspx. Accessed $24 \mathrm{Mar} 2015$

Pancsofar N, Vernon-Feagans L (2006) Mother and father language input to young children: contributions to later language. J Appl Dev Psychol 27(6):571-587

Parker K, Horowitz JM, Rohal M (2015) Parenting in America: outlook, worries, aspirations are strongly linked to financial situation. Pew Research Center, Washington DC

Parker K, Cilluffo A, Stepler R (2017a) 6 facts about the US military and its changing demographics. Pew Research Center, Washington, DC. https://wwwpewresearchorg/fact-tank/2017/ 04/13/6-facts-about-the-u-s-military-and-its-changing-demographics/. Retrieved 22 Nov 2020

Parker K, Horowitz JM, Stepler R (2017b) On gender differences, no consensus on nature vs. nurture. Pew Research Center, Washington, DC. https://www.pewsocialtrends.org/ 2017/12/05/americans-see-different-expectations-for-men-and-women/\#public-sees-more-pres sure-for-men-on-job-and-career-front

Paulson JF, Bazemore S (2010) Prenatal and postpartum depression in fathers and its association with maternal depression: a meta-analysis. JAMA 303(19):1961-1969

Pruitt MK, Pruitt KD, Cowan CP, Cowan PA, P. (2017) Enhancing paternal engagement in a co-parenting paradigm. Child Dev Perspect 11(4):245-250

Raeburn P (2014) Do fathers matter? Farrar, Straus, Giroux, New York

Ramchandani P, Stein A, Evans J, O’Connor TG, the ALSPAC Study Team (2005) Paternal depression in the postnatal period and child development: a prospective population study. Lancet 365(9478):2201-2205

Ramchandani PG, Psychogiou L, Vlachos H, Iles J, Sethna V, Netsi E, Lodder A (2011) Paternal depression: an examination of its links with father, child and family functioning in the postnatal period. Depress Anxiety 28(6):471-477

Reinherz HZ, Giaconia RM, Hauf AM, Wasserman MS, Silverman AB (1999) Major depression in the transition to adulthood: risks and impairments. J Abnorm Psychol 108(3):500-510

Rochlen AB (2005) Men in (and out of) therapy: central concepts, emerging directions, and remaining challenges. J Clin Psychol 61(6):627-631

Roggman LA, Boyce LK, Cook GA, Cook J (2002) Getting dads involved: predictors of father involvement in early head start and with their children. Infant Ment Health J 23(1):62-78

Sarkadi A, Kristiansson R, Oberklaid F, Bremberg S (2008) Father's involvement and children's developmental outcomes: a systematic review of longitudinal studies. Acta Paediatrica 97 (2): $153-158$

Shannon JD, Cabrera NJ, Tamis-LeMonda C, Lamb ME (2009) Who stays and who leaves: father accessibility across children's first 5 years. Parent Sci Pract 9(1-2):78-100

Smith TK, Darius Tandon S, Bair-Merritt MH, Hanson JL (2015) Parenting needs of urban African American fathers. Am J Mens Health 9(4):317-331

Teitler JO (2001) Father involvement, child health and maternal behavior. Child Youth Serv Rev 23 (4-5):403-425 
US Census Bureau (2013) Facts for features: father's day. June 16, 2013b. wwwcensusgov/ newsroom/facts-for-features/2013/cb13-ff13html. Accessed 24 Mar 2015

US Census Bureau (2018) Characteristics of same-sex couple households: 2018 table. https:// wwwcensusgov/data/tables/time-series/demo/same-sex-couples/ssc-house-characteristicshtml. Accessed 4 Mar 2020

US Census Bureau (2020) Fun facts: father's day. June 21, 2020. https://www2censusgov/ programs-surveys/sis/resources/fathers-day-ffpdf. Accessed 17 Nov 2020

Wainright JL, Russell ST, Patterson CJ (2004) Psychosocial adjustment, school outcomes, and romantic relationships of adolescents with same-sex parents. Child Dev 75(6):1886-1898. https://doi.org/10.1111/j.1467-8624.2004.00823.x

Wysocki T, Gavin L (2006) Paternal involvement in the management of pediatric chronic diseases: associations with adherence, quality of life, and health status. J Pediatr Psychol 31(5):501-511. https://doi.org/10.1093/jpepsy/jsj042

Yogman MW (1982) Development of the father-infant relationship. In: Fitzgerald H, Lester BM, Yogman MW (eds) Theory and research in behavioral pediatrics, vol 1. Plenum Press, New York, pp 221-279

Yogman MW, Lester BM, Hoffman J (1983) Behavioral and cardiac rhythmicity during motherfather-stranger infant social interaction. Pediatric Res 17(11):872-876. https://doi.org/10.1203/ 00006450-198311000-00007

Yogman MW, Garfield CF, AAP the Committee on Psychosocial Aspects of Child, Family Health (2016) Fathers' roles in the care and development of their children: the role of pediatricians. Pediatrics 138(1):e20161128

Open Access This chapter is licensed under the terms of the Creative Commons Attribution 4.0 International License (http://creativecommons.org/licenses/by/4.0/), which permits use, sharing, adaptation, distribution and reproduction in any medium or format, as long as you give appropriate credit to the original author(s) and the source, provide a link to the Creative Commons license and indicate if changes were made.

The images or other third party material in this chapter are included in the chapter's Creative Commons license, unless indicated otherwise in a credit line to the material. If material is not included in the chapter's Creative Commons license and your intended use is not permitted by statutory regulation or exceeds the permitted use, you will need to obtain permission directly from the copyright holder.

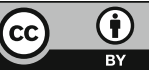

